\title{
Anschauungsunterricht ...
}

Mit einer kurzen Notiz in dieser Ausgabe der Schweizerischen Ärztezeitung wird darauf hingewiesen, dass die Unfallversicherer, vertreten durch die MTK, seit Anfang Jahr Abfragen auf der Dignitätsdatenbank der FMH vornehmen können. Sie haben recht, dies ist nicht spektakulär, hier werden Vereinbarungen zwischen den Partnern endlich umgesetzt - nach nunmehr sechs Jahren. Dies ist keine grossartige Leistung, also eigentlich keines weiteren Kommentars wert.

Für mich lohnt sich dennoch ein kurzes Verweilen bei diesem Thema. Mir wurde das Dossier Dignitätsdatenbank am Abend meiner Wahl in den Zentralvorstand, vor gut dreieinhalb Jahren, übergeben. Dieses Dossier hat mich während der ganzen Zeit begleitet; mit der Inbetriebnahme der Abfrage kann ich es nun abschliessen.

Während der Umsetzung sind mir verschiedene «Weltanschauungen» eindrücklich in Erinnerung gerufen worden. Obwohl die vertragliche Grundlage einfach und eindeutig ist, wurde immer wieder versucht, uns als Ärzteschaft massiv unter Druck zu setzen und damit die Herausgabe der vollständigen Datenbank an die Versicherer zu erzwingen. Kein Vorwand, kein Trick war faul genug, um nicht auch ausprobiert zu werden. Wir wurden genötigt, beschimpft, der Inkompetenz bezichtigt, desavouiert. Diese «Strategie» hat ihr Ziel glückli- cherweise verfehlt. Erfolgreich war letztlich ein pragmatischer Ansatz: Zusammen mit unseren Partnern von der MTK gelang es, die offenen Fragen im gegenseitigen Respekt, in Anerkennung der vertraglichen Grundlagen anzugehen und eine einfache Lösung gemeinsam zu entwickeln.

Dies ist ja eigentlich auch kein grosses Meisterstück. Für mich ist es jedoch ein Lehrbeispiel dafür, wie wir in der Standes- und Berufspolitik Lösungen erreichen können. Wir können die Themen «machtpolitisch» besetzen und geraten damit sofort in eine Rauferei. Oder wir stellen die offenen Fragen ins Zentrum, begegnen uns mit Respekt und nutzen die Erfahrung der Partner zur Lösungsfindung. Wir sind frei, den einen oder den andern Ansatz zu wählen - wir und unsere Partner bzw. Kontrahenten entscheiden dies bei jedem «Geschäft» neu.

Wir stehen am Anfang eines neuen Jahres, gleichzeitig am Ende unserer Amtsdauer als Mitglieder des Zentralvorstandes. Für mich steht fest, mir gefällt diese Arbeit, ich helfe gerne mit - konstruktiv, pragmatisch und für den einen oder anderen vielleicht etwas zu beharrlich -, überzeugende Resultate zu erreichen.

Ich bedanke mich bei all denen, die mitgeholfen haben und weiterhin mithelfen.

Dr. med. Olivier Kappeler, Mitglied des Zentralvorstandes der FMH 